\title{
The role of pores and microstructural heterogeneity on the tooth root fatigue strength of sintered spur gears
}

\author{
Matteo Benedetti ${ }^{1}$, Vigilio Fontanari ${ }^{*}$, Alberto Molinari ${ }^{1}$, Pietro Valcozzena ${ }^{1}$, and Wolfgang Pahl $^{2}$ \\ ${ }^{1}$ Department of Industrial Engineering, University of Trento, 38122 via Sommarive 9, Trento, Italy \\ ${ }^{2}$ GKN Sinter Metals, 39031 via delle Fabbriche 5, Brunico (BZ), Italy
}

\begin{abstract}
The automotive industry employs a considerable amount of sintered parts, mainly as transmission and engine components. Gears are the parts that mostly benefit, in terms of cost saving, from the near net shape $\mathrm{P} / \mathrm{M}$ technology. However, the porosity along with the heterogeneous microstructure can detrimentally affect the mechanical behaviour, especially the fatigue strength. The possibility of increasing sintered density up to $90 \%$ and more, the use of high strength alloys, as well as post sintering treatments have been extensively investigated obtaining consistent increases in the fatigue strength. The present study focuses on the effects of porosity and microstructure on tooth root bending fatigue of small module spur gears. The aim is to investigate the synergistic contribution of pore morphology and microstructure heterogeneity to the initiation of fatigue cracks and to the following crack paths. High density parts produced by high strength pre-alloyed powders were studied. Part of the specimens was case-hardened to obtain a martensitic/bainitic microstructure in the surface layer. Bending fatigue tests up to a fatigue endurance of three million cycles were performed. A careful fractographic analysis was conducted. The obtained results were discussed using the fracture mechanics approach of Murakami, considering the pores as pre-existing defects, whose propagation strongly depends on the microstructural heterogeneity.
\end{abstract}

\section{INTRODUCTION}

The structural parts produced by powder metallurgy $(\mathrm{P} / \mathrm{M})$ represent a competitive solution, alternative to traditional production, in many industrial sectors, including the automotive industry that employs a considerable portion of the total production of $\mathrm{P} / \mathrm{M}$ parts.

The progressive improvement of the production processes has led to the design and fabrication of structural parts able to withstand high stress levels. The gears represent one of these applications, where maximum advantages in terms of competitiveness and quality can be achieved by using a near net shape technique such as $\mathrm{P} / \mathrm{M}$ [1-5].

The research efforts have always been devoted to setting up processes able to increase the relative density of the sintered parts up to $90 \%$ and more; in addition, the formulation of new high strength pre-alloyed powders and the development of surface modification techniques have strongly improved the 'in service' performances as well as the quality of the final product. Despite this positive trend, some crucial aspects still remain open. One of these is the comprehension of the synergistic effect of porosity and microstructure in the damage process of the material when subjected to 'in service' loads [6-10]. This aspect turns out to be particularly critical for structural pieces that work under cyclic loading conditions and are therefore prone to fatigue damage. It can be observed that, for relatively low sintered density, the damage usually occurs very early, located at the necks between powder particles, which are the weakest point of the microstructure. A widespread damage occurs and the final failure is often caused by the coalescence of numerous defects previously initiated [11]. By increasing the sintered density to high values, even up to near-full density, the triggering of the damage is delayed and the pores can be regarded as local defects of different criticality, able to concentrate the stresses and to act as internal notches or, in certain situations, even as cracks $[5,12$ to 15$]$. In this case the fatigue response is dictated by the most critical defect, which is generally an irregularly shaped pore located in the regions of maximum stress.

The microstructural heterogeneity can play a very important role in the damage localization and in the definition of a preferential crack path $[5,8]$. Particularly critical are the soft phases that usually envelop the critical pores and represent the microstructure of first propagation of the fatigue crack.

In some papers [6-8], the pores are treated as preexisting cracks and a fracture mechanics approach is adopted to predict the propagation conditions of cracklike defects. The Murakami criterion [16], initially proposed for determining the fatigue limit of steels containing inclusions, can be very promising among the fracture mechanics based methods. In particular, in its most general formulation this approach envisages estimating the fatigue limit of the material with the

Corresponding author: vigilio.fontanari@unitn.it 
following equation, that includes also the influence of the load ratio $R$.

$$
\sigma_{\text {lim }}=C \cdot \frac{H V+120}{(\sqrt{\text { area }})^{1 / 6}} \cdot\left(\frac{1-R}{2}\right)^{\alpha}
$$

The Vickers hardness HV accounts for the effect of the microstructure, whereas the term 'area' contains the information on the defect geometry, i.e. the dimension of the defect projected on the critical plane of crack propagation, characterized by the maximum normal stress (opening mode I). Finally, $\mathrm{C}$ and $\alpha$ are empirical parameters related respectively to the position of the pore with respect to the surface and to the material microstructure. In particular $\mathrm{C}=1.41$ for surface defects, $\mathrm{C}=1.56$ for internal defects, while the exponent $\alpha=$ $0.226+\mathrm{HV} \cdot 10^{-4}$.

Bergmark [6] used the Murakami model for sintered products by introducing a further corrective factor that indirectly takes into account the effect of porosity in terms of variation of the elastic modulus with respect to that of the fully dense material.

A critical aspect for the application of the Murakami model concerns the definition of the critical pore and the identification of the hardness that has to be included in the formula.

In the context of this research topic, the present work is aimed at investigating the tooth root fatigue behaviour of small module spur gears produced by $\mathrm{P} / \mathrm{M}$ technology, starting from different pre-alloyed powders, compacted up to high green density and consolidated adopting different sintering conditions. The principal objective is to explore the synergic effect of pore structure and microstructure on the fatigue behaviour. For this reason, the fatigue response is discussed starting from an in-depth fractographic analysis aimed at identifying the role of porosity and microstructure in the initiation and propagation of cracks. The Murakami model is applied for distinguishing the synergistic role of porosity and heterogeneous microstructure in defining the fatigue limit of the material.

\section{EXPERIMENTAL ACTIVITY}

The experimental activity was carried out on the $\mathrm{P} / \mathrm{M}$ spur gears shown in Fig. 1, whose main constructive parameters are: number of teeth $\mathrm{N}=20$, module $\mathrm{m}=0.71$ $\mathrm{mm}$ and pressure angle $\theta=20^{\circ}$.

The tooth root bending fatigue strength for three types of material is investigated. The reference standard is ISO 6336 [17] for the calculation of the load capacity of spur and helical gears.

The gears are produced using pre-alloyed as well as diffusion bondend powders, whose nominal compositions are summarized in Table 1.

In the blending phase, carbon in the form of graphite is added in a quantity equal to $0.25 \%$ wt for $\mathrm{A} 85 \mathrm{Mo} 05$, and $0.15 \%$ wt both for DHP and DDH.
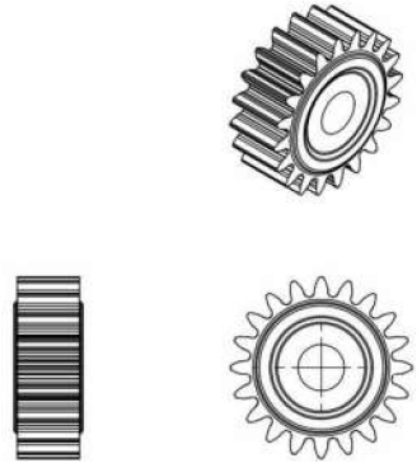

Fig. 1. Geometry of the $\mathrm{P} / \mathrm{M}$ spur gears.

Table 1. Nominal compositions of the powders

\begin{tabular}{|c|c|c|}
\hline $\begin{array}{c}\text { Powder } \\
\text { label }\end{array}$ & Composition (\%wt) & \\
\hline A85Mo05 & $0.85 \mathrm{Mo}, \mathrm{Fe} \mathrm{bal.}$ & pre-alloyed \\
\hline $\mathrm{DHP}$ & $1.5 \mathrm{Mo}, 2.0 \mathrm{Cu}, 4.0 \mathrm{Ni}, \mathrm{Fe}$ bal & $\begin{array}{c}\text { diffusion } \\
\text { bonded }\end{array}$ \\
\hline $\mathrm{DDH}$ & $1.5 \mathrm{Mo}, 2.0 \mathrm{Cu}, \mathrm{Fe}$ bal & $\begin{array}{c}\text { diffusion } \\
\text { bonded }\end{array}$ \\
\hline
\end{tabular}

The gears were produced by GKN Sinter Metals. For A85Mo05 a conventional sintering cycle was conducted in a continuous furnace at a temperature of $1120{ }^{\circ} \mathrm{C}$ for $30 \mathrm{~min}$ in an atmosphere of endogas (A85Mo05); DDH and DHP underwent to a sinter-hardening cycle that provides forced cooling from the temperature of $1120^{\circ}$ $\mathrm{C}$ down to $300{ }^{\circ} \mathrm{C}$, followed by stress relieving in a separate oven at $180^{\circ} \mathrm{C}$ for $1 \mathrm{~h}$. The A85Mo05 gears were case hardened (austenitizing at $860^{\circ} \mathrm{C}$ with oil quenching) after sintering to improve the mechanical behaviour of the surface layer.

\subsection{Microstructure and porosity}

The density was measured using the Archimedes method according to ASTM B311, which permits a quantitative evaluation of the total and open porosity. The porosity was also studied by image analysis using an optical microscope, in order to identify the pores morphology and also their spatial distribution in the gear body. In particular, local measurements were carried out at the tooth root, as well as inside the tooth and in the gear body. Table 2 lists the mean porosity values calculated according to ASTM B311, while table 3 reports the results of the image analysis measurements. It can be observed that porosity has a non-homogeneous distribution into the gear volume.

Table 2. mean density, total porosity and open porosity following ASTM B311.

\begin{tabular}{|c|c|c|c|}
\hline & A85Mo05 & DHP & DDH \\
\hline Density $\left(\mathrm{gcm}^{-3}\right)$ & 7.55 & 7.35 & 7.41 \\
\hline Total porosity $(\%)$ & 4.09 & 7.56 & 6.36 \\
\hline Open porosity(\%) & 0.60 & 1.39 & 0.96 \\
\hline
\end{tabular}


Table 3. mean porosity values in different regions of the gear measured using image analysis on metallographic sections.

\begin{tabular}{|c|c|c|c|}
\hline Porosity \% & A85Mo05 & DHP & DDH \\
\hline Tooth body & 7.13 & 8.85 & 7.63 \\
\hline Tooth root & 6.29 & 7.99 & 6.20 \\
\hline gear body & 3.04 & 7.15 & 4.17 \\
\hline
\end{tabular}

The A85Mo05 specimens contains irregularly shaped pores, not uniformly distributed in the gear volume: the remarkable difference in pores content between the tooth and the gear body is evident (table 3). While A85Mo05 exhibits the lowest total porosity among the three variants, its pore content in the critical tooth root region is comparable with other materials. Concerning the microstructure (fig. 2), a surface layer with martensitic microstructure and limited presence of bainite and retained austenite can be observed. The bulk is instead characterized by lower bainite and martensite.

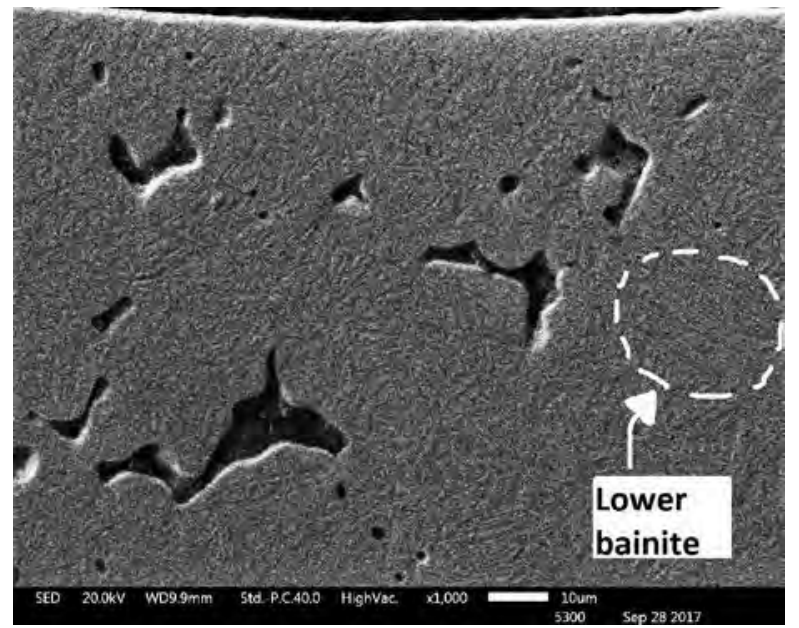

Fig. 2. Microstructure of A85Mo05

The DHP steel is characterized by a more homogeneous pore distribution in the gear volume. The microstructure is heterogeneous (fig. 3) with austenite (white areas), lower bainite (light gray areas) and martensite (dark gray areas). The distribution of the alloy elements is inhomogeneous in the diffusion bonded powders and during sintering there is no complete diffusion of $\mathrm{Ni}$ and $\mathrm{Cu}$ into the base powders $(1.5 \% \mathrm{Mo}$ Prealloyed iron). The Ni-rich austenite is predominantly located around the pores [18]. The martensite is richer in $\mathrm{Cu}$, while the base powder, poor in $\mathrm{Ni}$ and $\mathrm{Cu}$, is predominantly bainitic.

The DDH steel shows a non-uniform pore distribution, comparable to A85Mo05. The microstructure (fig. 4) is predominantly martensitic in the surface layer with some evidences of lower bainite, while the upper bainite prevails in the bulk. Also in this case the pre-alloyed powders do not presents a homogeneous distribution of $\mathrm{Cu}$, consequently areas richer in $\mathrm{Cu}$ are still present after sintering and assume a martensitic microstructure upon cooling.

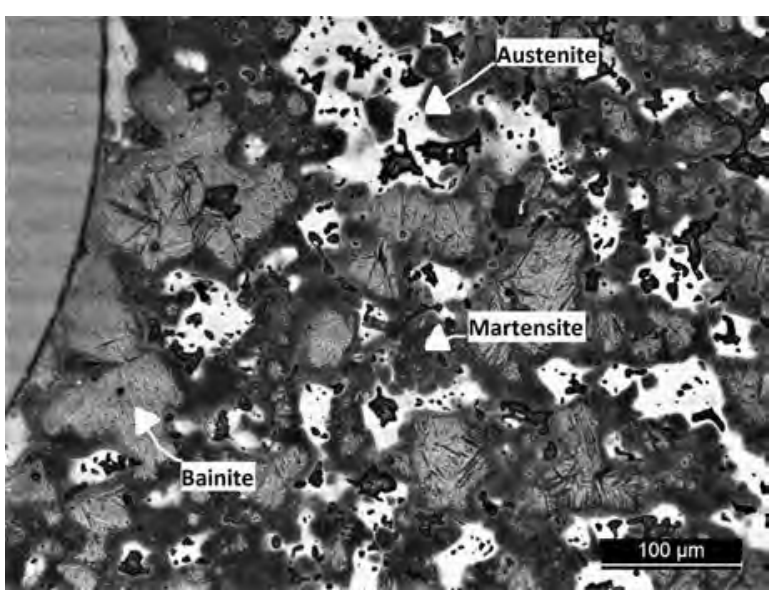

Fig. 3. Microstructure of DHP

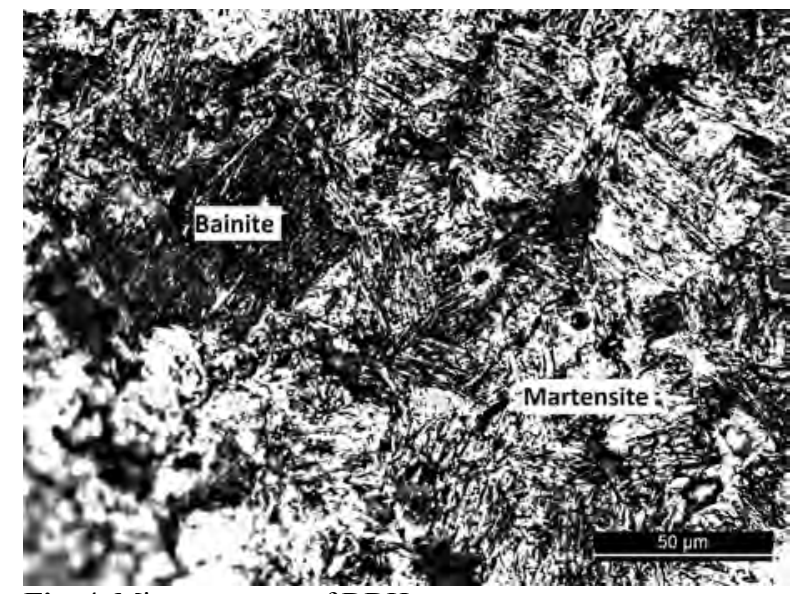

Fig. 4. Microstructure of DDH

Due to the post sintering treatments, all the materials are characterized by a surface layer with higher hardness compared to the bulk one. The A85Mo05 alloy was modified by case-hardening, while the other two material variants are produced by sinter-hardening, undergoing a controlled cooling from the sintering temperature down to $300{ }^{\circ} \mathrm{C}$, whose effects are more evident in the surface layer. The microhardness profiles $\left(\mathrm{HV}_{0.05}\right)$ are plotted in figure 5: the surface hardening extends to a depth of nearly $0.5 \mathrm{~mm}$.

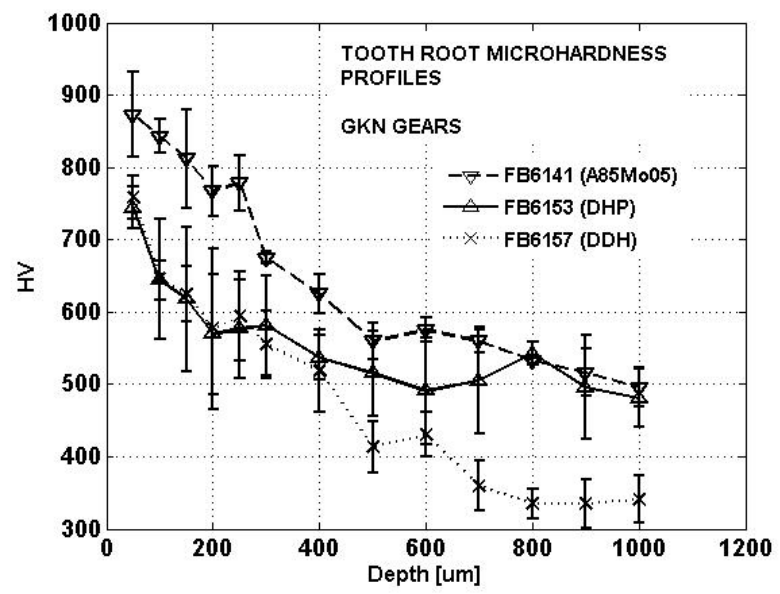

Fig. 5. Microhardness profiles in the surface layer 


\subsection{Fatigue testing}

The fatigue tests were conducted with a resonant Rumul Mikroton $20 \mathrm{kN}$ testing machine operating at frequencies of about $150 \mathrm{~Hz}$. The testing configuration shown in fig. 6 provides for the simultaneous gripping of two teethwith intespaciong of five teeth.

Unfortunately, due to the very small module of the teeth, this condition cannot be precisely reproduced by the testing configuration. For this reason, the stress state in the tooth root region is evaluated with a finite element analysis, that allows to model the effective testing configuration: In this way stress at the tooth root can be correctly calculated. 20-node brick element were used to build up the FE model. The sub-modelling technique was adopted to obtain a refined evaluation of the local stress. The FEM sub-model developed for the analysis is shown in fig. 7. The FE convergence analysis was performed by reproducing the ISO 6336 loading configuration and comparing the FE tooth root bending stress with that calculated using the ISO6336 formula.

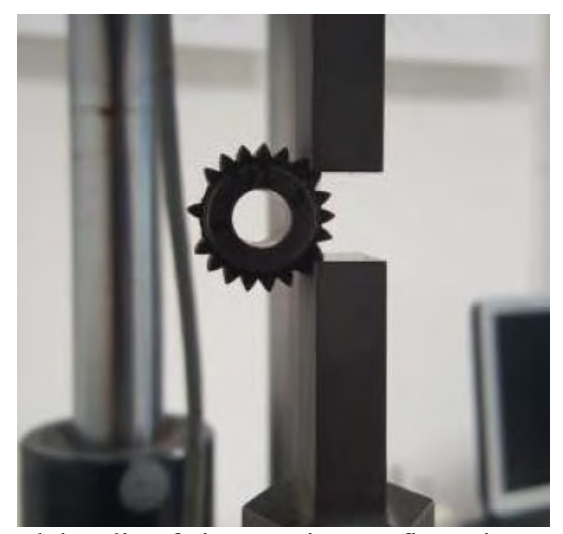

Fig. 6. Tooth bending fatigue testing configuration

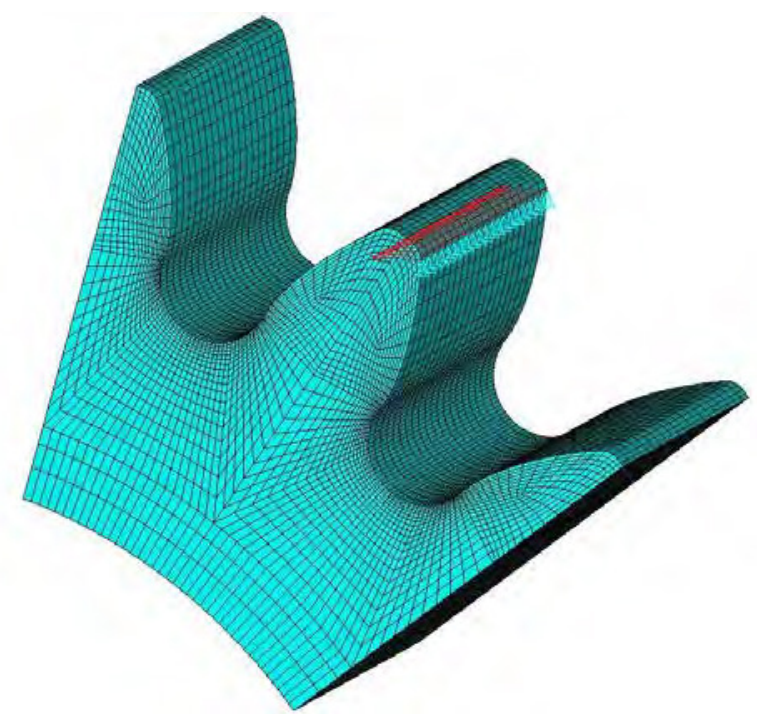

Fig. 7. FEM Sub-model of the loaded tooth: the applied loads are represented by the red arrows.

A load ratio $\mathrm{R}$ of 0.1 was adopted. A fatigue life interval between $3 \cdot 10^{4}$ and $3 \cdot 10^{6}$ cycles was explored. The fatigue strength at $3 \cdot 10^{6}$ cycles was determined using the staircase method performing at least 15 tests.
Specimens surviving the $3 \cdot 10^{6}$ cycles are considered as runouts. The choice of $3 \cdot 10^{6}$ cycles is dictated by the ISO6336 standard. In fact, for this fatigue live, an endurance factor equal to one is assumed in the design formula.

The fatigue curve in the finite life regime was evaluated using the Basquin law reported by Eqn. 2. A least-square regression of the results of 15-20 tests, distributed on different stress levels was carried out:

$$
\sigma_{a} \cdot N^{1 / m}=C
$$

In this formula $\sigma_{\mathrm{a}}$ represents the stress amplitude and $\mathrm{N}$ is the number of cycles to failure. The dispersion of the results is calculated using the central standard deviation of the data, assuming uniform scatter for different fatigue lives. A measure of the results scattering is expressed by the ratio between the stress amplitude corresponding to $90 \%$ and $10 \%$ probability of failure:

$$
T_{\sigma, 10: 90}=\frac{\sigma_{a, 90}}{\sigma_{a, 10}}
$$

The evidence of a knee in the fatigue curve at fatigue lives lower than about $2 \cdot 10^{6}$ cycles may be indicative of the presence of a fatigue limit, the confirmation thereof would however require investigating the response to longer lifetimes. In the figures 8-10 the results of the bending fatigue tests and the $\mathrm{P}_{10}, \mathrm{P}_{50}$ and $\mathrm{P}_{90}$ fatigue curves are plotted.

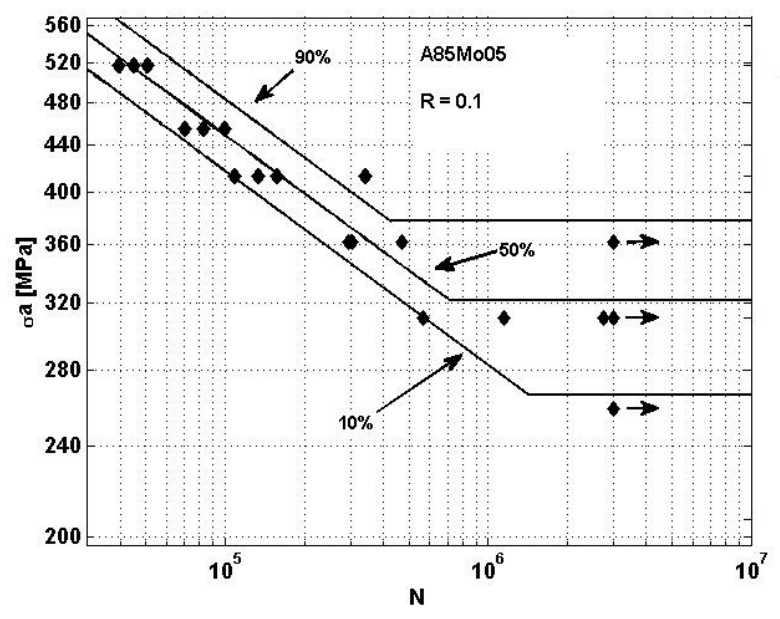

Fig. 8. Results of bending fatigue tests on $\mathrm{A} 85 \mathrm{Mo} 05$

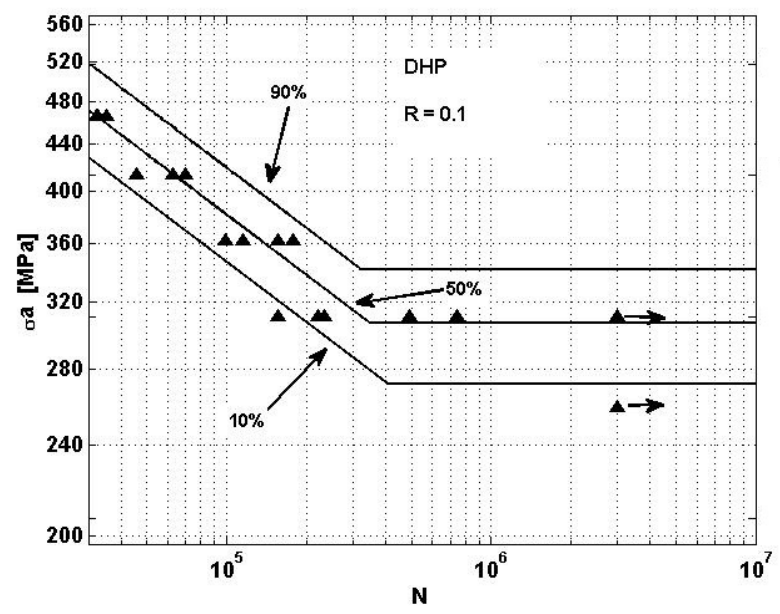


Fig. 9. Results of bending fatigue tests on DHP

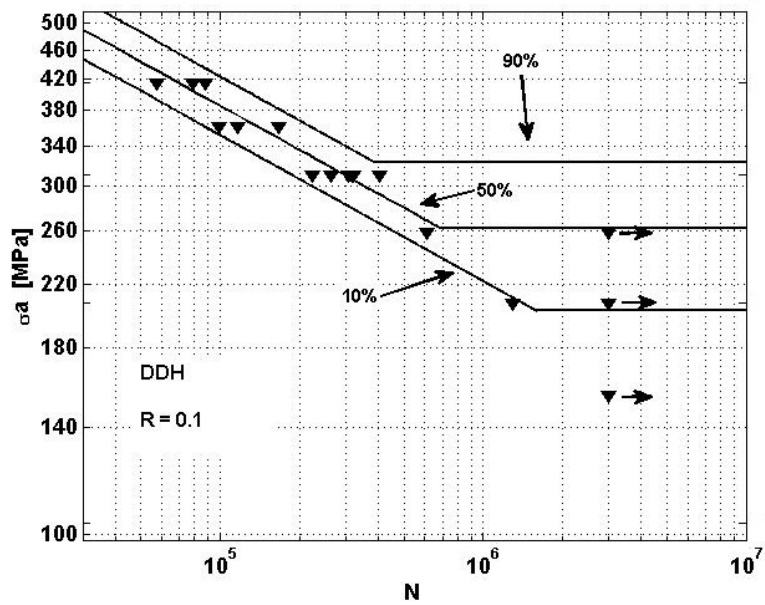

Fig. 10. Results of bending fatigue tests on DDH

The principal parameters that describe the fatigue behaviour for the three materials are collected in table 4 .

Table 4. Characteristic parameters of the fatigue curves.

\begin{tabular}{|c|c|c|c|l|}
\hline & $\sigma_{a, 3 \cdot 10^{6}}\left(\mathrm{P}_{50}\right)$ & $T_{\sigma, 10: 90}$ & $\mathrm{C}$ & $\mathrm{m}$ \\
\hline A85Mo05 & $321(\mathrm{MPa})$ & 1.42 & $3163(\mathrm{MPa})$ & 5.90 \\
\hline DHP & 307 & 1.26 & 2858 & 5.71 \\
\hline DDH & 262 & 1.59 & 3846 & 5.00 \\
\hline
\end{tabular}

The obtained results are compared with results published in [3-5] for similar microstructures with different porosity contents. In general, the literature data show a progressive but not particularly marked decrease in the fatigue strength with density for relative densities higher than $90 \%$, whereas a very marked worsening occurs at lower densities.

\subsection{Fractographic analysis}

The fractographic study was carried out both by metallographic observations and by electron scanning microscopy (SEM) analysis. In the first case, the main objective is to study the preferential crack path, whereby the tooth is sectioned with a plane orthogonal to the gear axis, polished and prepared with the conventional metallographic procedure. The SEM analysis, on the other hand, is aimed at identifying the crack initiation sites and at evaluating the size of the critical pores.

The representative images for the three material variants are shown in the following figures. The crack path for A85Mo05 (Fig. 11a) is not very serrated: a limited evidence of deviations due to the presence of porosity can be observed. In fig. $11 \mathrm{~b}$ a surface pore is highlighted which has probably played the role of crack initiation site. In the same region some evidences of intergranular fracture have been observed, that is probably produced by grain boundary embrittlement due to cementite precipitation after carbon enrichment during case hardening.
The fracture path for DHP (Fig. 12) and for DHH (Fig. 13) is much more influenced by the presence of pores that define preferential propagation directions and determined a very serrated path

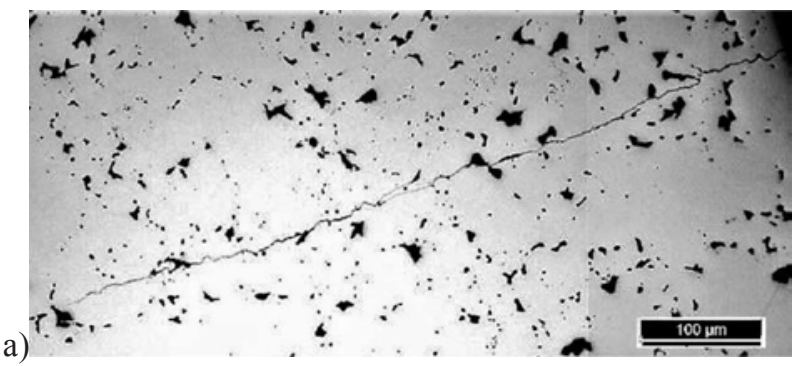

b)

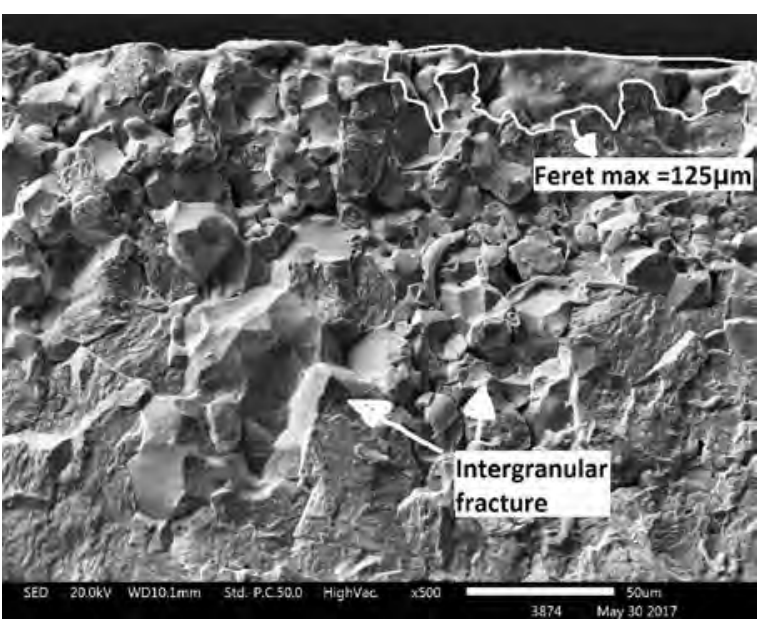

Fig. 11. A85Mo05: a) crack path, b) initiation site

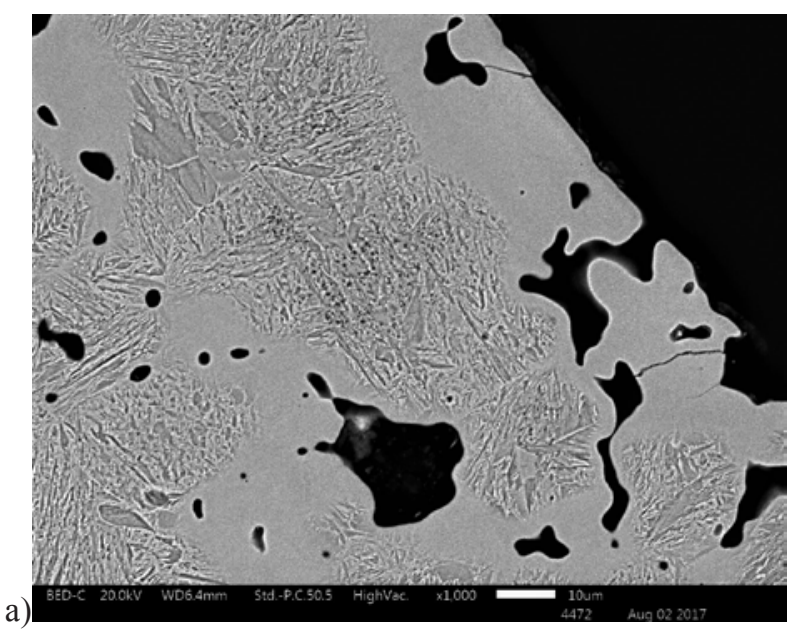




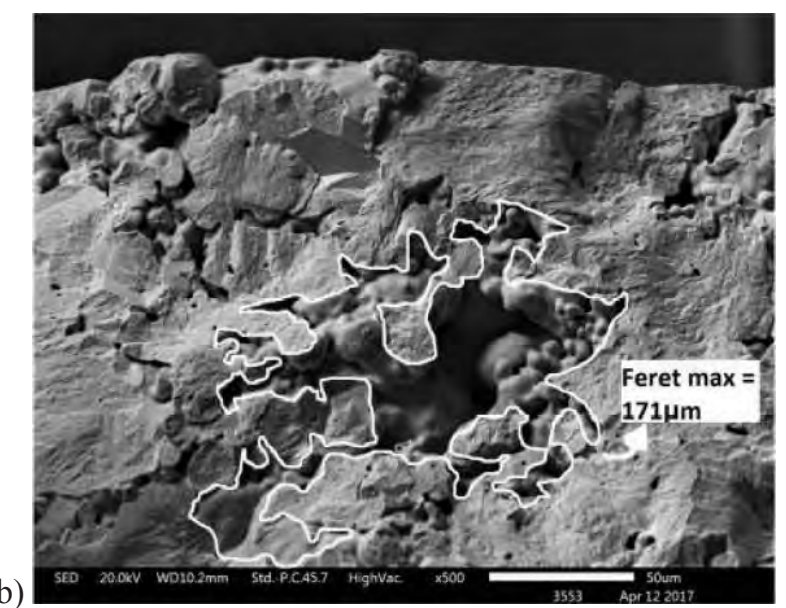

Fig. 12. DHP: a) crack path, b) initiation site

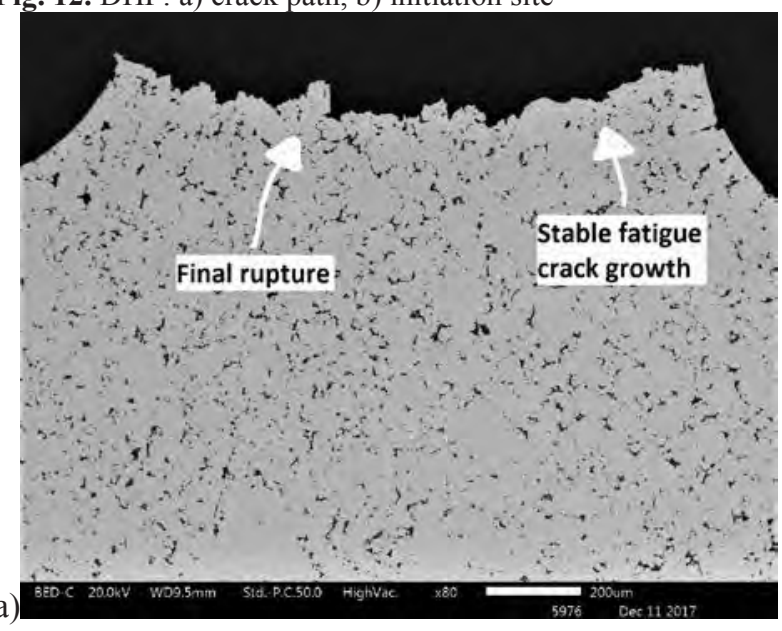

b)

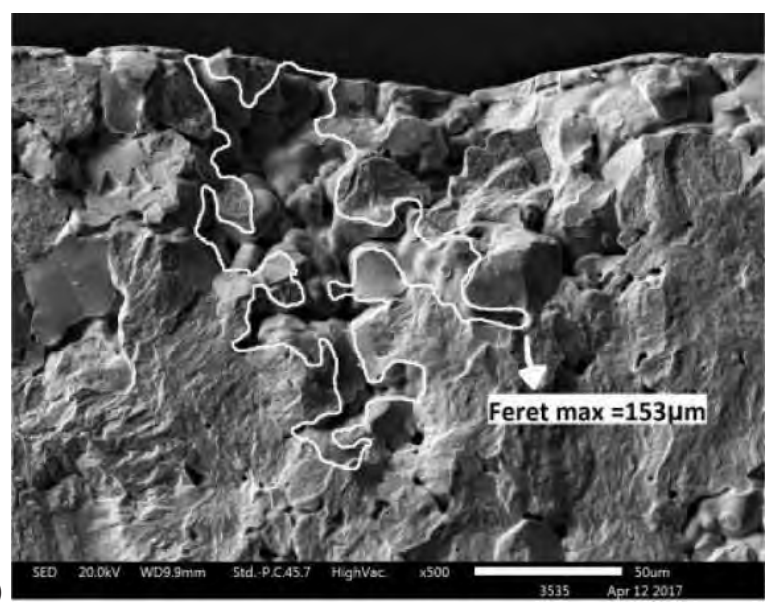

Fig. 13. DDH: a) crack path, b) initiation site

For both material variants the SEM analysis allows to identify pores with very articulated morphology close to the surface, which can be reasonably considered as initiation sites for the fatigue crack. Some evidences of multiple crack initiation followed by crack coalescence have been observed.

Both for DDH and DHP, small cracks nucleated at pores proximal to the tooth surface (Fig. 14) have been observed. This suggests the occurrence of a first stage of diffused damage with multiple crack nucleation, followed by the onset of a main crack that can connect several cracks in its propagation path. The cracks not involved in this process of coalescence stop growing as that shown in figure 14. This observation agrees with the crack propagation behaviour reported in the technical literature $[5,8,12,13]$.
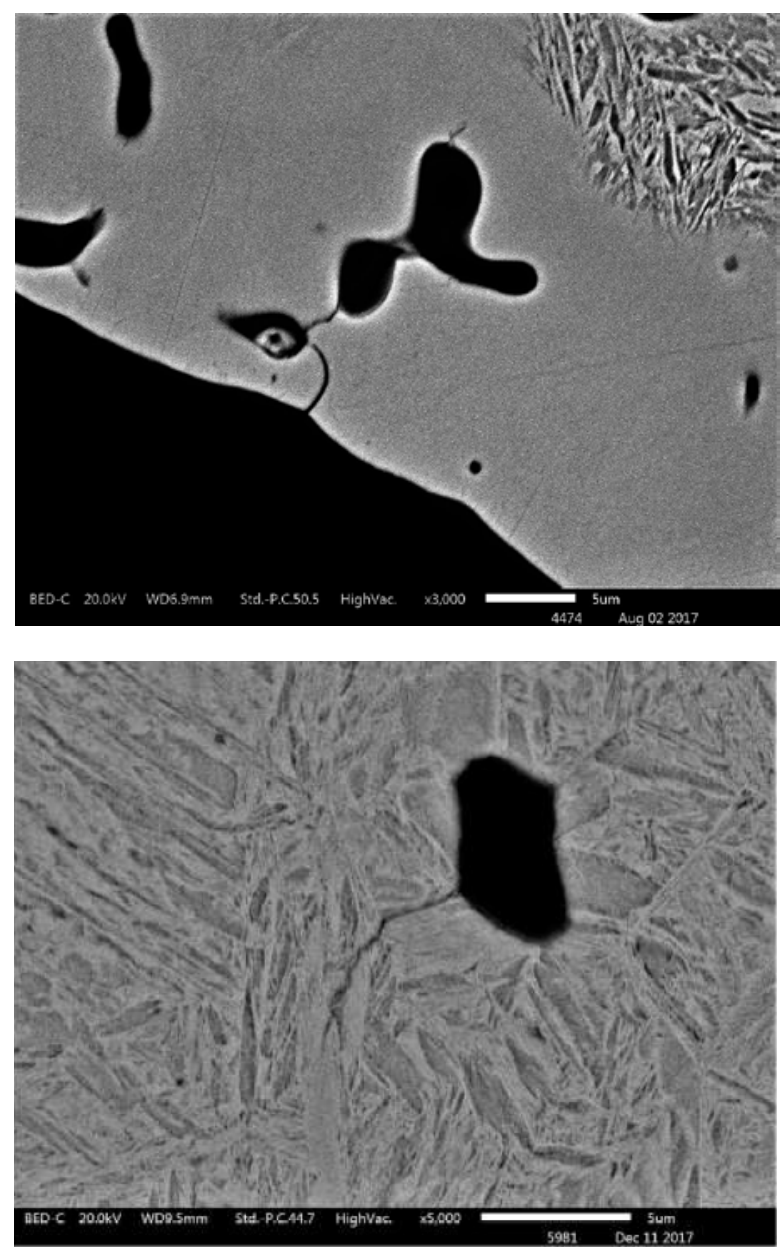

Fig. 14. DDH: non propagating cracks

An extensive analysis of the most critical pores on the fracture surface was carried out to estimate the characteristic size of the initial defect to be used in the Murakami formula. To calculate the area of the critical pores the maximum Feret diameter is used, the evaluation of which is schematically described in figure 15. The area to be inserted in equation 1 is that of the circle defined by the maximum Feret diameter, that inscribes the pore. 


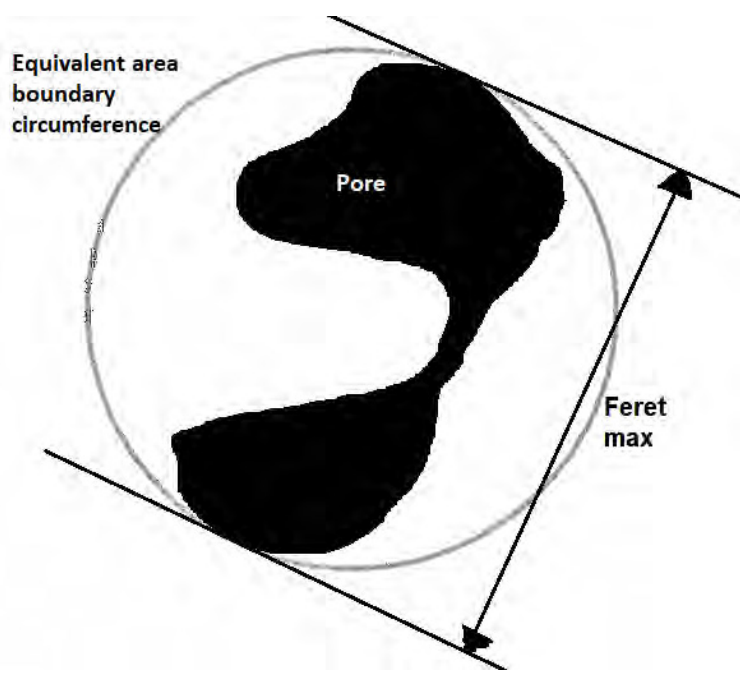

Fig. 15. Scheme for the evaluation of the characteristic dimension of the pore, defined by the Feret diameter

For the evaluation of the fatigue strength using the Murakami model it is necessary to provide the hardness value representative of the material microstructure. The microstructural heterogeneity produced by the nonuniform distribution of the alloying elements can play an important role. The significant differences between the bulk microstructure and the phase surrounding the pores were previously highlighted (fig. 2). To shed light on the role of the local microstructure, the estimate of the fatigue strength using the Murakami model has been realized both considering the average hardness of the material and the local hardness taken in the surroundings of the pores, which characterizes the microstructural phase in which the crack initiation occurs. The results are collected in tables 5 and 6 and compared with the experimental values.

Table 5. Fatigue strength estimated with the Murakami model considering the average microstructural hardness

\begin{tabular}{|c|c|c|c|c|c|}
\hline & $\begin{array}{c}\text { HV } \\
\text { mean }\end{array}$ & $\begin{array}{c}\sqrt{\text { area }} \\
(\mu \mathrm{m})\end{array}$ & $\begin{array}{c}\sigma_{\mathrm{l}, \mathrm{Mur}} \\
(\mathrm{MPa})\end{array}$ & $\begin{array}{c}\sigma_{\mathrm{l}, \text { exp }} \\
(\mathrm{MPa})\end{array}$ & $\Delta(\%)$ \\
\hline A85Mo05 & 873 & 111 & 524 & 321 & +63 \\
\hline DHP & 744 & 152 & 437 & 307 & +42 \\
\hline DDH & 758 & 136 & 452 & 262 & +73 \\
\hline
\end{tabular}

Table 6. Fatigue strength estimated with the Murakami model considering the local hardness.

\begin{tabular}{|c|c|c|c|c|c|}
\hline & $\begin{array}{c}\text { HV } \\
\text { local }\end{array}$ & $\begin{array}{c}\sqrt{\text { area }} \\
(\mu \mathrm{m})\end{array}$ & $\begin{array}{c}\sigma_{\mathrm{l}, \mathrm{Mur}} \\
(\mathrm{MPa})\end{array}$ & $\begin{array}{c}\sigma_{\mathrm{l}, \exp } \\
(\mathrm{MPa})\end{array}$ & $\Delta \%$ \\
\hline A85Mo05 & 515 & 111 & 345 & 321 & +7 \\
\hline DHP & 325 & 152 & 233 & 307 & -24 \\
\hline DDH & 378 & 136 & 264 & 262 & +1 \\
\hline
\end{tabular}

A consistent improvement in the estimation of the fatigue strength is obtained using the local hardness in the Murakami formula. This result confirms, even considering the approximations introduced for the evaluation of the critical defect size, the considerable role played by the microstructure in the neighbourhood of the critical pores. From another point of view, it is worth noticing that the initiation phase, spent by the cracks propagating trough the microstructural phases enveloping the pores, takes a large part of the entire fatigue life.

Moreover, a plausible explanation of the different errors obtained for the three variants can be given. As far as $\mathrm{A} 85 \mathrm{Mo05}$ is concerned, the overestimation may be due to the fact that the grain boundary embrittlement occurring in the case hardened layer is not taken into account by the Murakami model. On the contrary, for the sinter-hardened DHP material, characterized by soft austenite surrounding the critical pores, an underestimation of the fatigue strength is obtained. This can be due by the partial or total transformation of the retained austenite into martensite with consequent local increase in volume, that can produce crack closure slowing propagation speed or even leading to arrest the fatigue crack. These hypotheses need to be confirmed with a more in-depth study.

\section{Conclusions}

The tooth root bending fatigue behaviours for three P/M material variants characterized by high density and high strength microstructures were studied. The main conclusions can be listed as follows:

1) the fatigue curves have a marked knee that can suggest to consider the fatigue strength at $3 \cdot 10^{6}$ cycles as a reasonable estimate of the fatigue limit. However, the scatter of the fatigue results is quite large and therefore additional tests will be needed to explore longer fatigue lives.

2) by studying the porosity distribution and morphology as well as the inhomogeneous microstructure after sintering characterized by evident differences in hardness, the factors that most affect the fatigue response can be evaluated.

3) The SEM analysis of the fracture surfaces allows to identify the critical pores and to advance the hypothesis that the main crack is formed as a result of the coalescence of multiple cracks nucleated in the most stressed region.

4) For the evaluation of the critical pore it is necessary to conduct the SEM fractographic analysis, as the metallographic analysis does not allow to clearly identify the pores criticality. The pore area identified by SEM observation on the fracture surface approaches that of the crack surface projected on the critical plane, as required by the Murakami model

5) The representative parameter of the pore criticality can be the maximum Feret diameter, which identifies the circumference inscribing the serrated perimeter of the pore

6) The application of the Murakami method allows to highlight the remarkable importance of the microstructure, which acts synergistically with the pore in the damage localization 


\section{References}

1. C.M. Sonsino CM., Powder Metall., 33(3), 235-245, (1990)

2. P.K Jones, K. Buckley-Golder, R. Lawcock et al., Int J Powd Metall., 33(3), 37-44, (1997).

3. L. Forden, S. Bengtsson, M. Bergström,. Powder Metall., 48(1):10-12, (2005)

4. S. Dizdar, P. Johansson, Proceedings of EURO PM2007, Toulouse, France; 1-7, (2007).

5. M. Benedetti, C. Menapace, Powder Metallurgy, 60 (2), 149-156, (2017)

6. A. Bergmark, Powder Metallurgy Progress, 5(3), 131-137, (2005)

7. M. Andersson, Powder Metallurgy Progress, 11 (12), 21-3,1 (2011)

8. G. Straffelini, V. Fontanari, A. Hafez, M. Benedetti, Powder Metallurgy, 52(4), 298-303, (2009)

9. J.M. Torralba, L. Esteban, E. Bernardo, et al., Powder Metall. 57(5):357-364, (2014)

10. H. D'Armas, L. llanes, J. Penafiel, J. Bas, M. Anglada, Mater Sci Eng A.;277:291-296. (2000)

11. G. Straffelini, M. Benedetti, V. Fontanari, Materials and Design, 61, 101-108, (2014)

12. M. Kabatova, E. Dudrova, A. S. Wronski, Fat. Fract. Engng Mat., 32, 214-222, (2009)

13. E. Dudrova, M. Kabatova, Powder Metall. 59(2):148-167, (2016)

14. Danninger H, Xu C, Khatibi G, B Weiss, B Lindqvist, Powder Metall. 55(5):378-387, (2012)

15. X. Deng, G.Piotrowski, N.Chawla, K.S. Narasimhan, Mat. Sc. Engng. A, 491(1-2), 28-38, (2008)

16. Y. Murakami, Y.: Metal Fatigue: effects of small defects and nonmetallic inclusions. Oxford (UK) Elsevier Science Ltd., (2002)

17. ISO 6336-1:2006, Calculation of load capacity of spur and helical gears. (2006)

18. F. Bernier F, P. Plamondon, J-P. Bailon, G. L'Esperance, Powder Metall 2011;54:559-65. 